\title{
The significant impact of aerosol vertical structure on lower atmosphere stability and its critical role in aerosol-planetary boundary layer (PBL) interactions
}

\author{
Tianning Su${ }^{1}$, Zhanqing $\mathrm{Li}^{1}$, Chengcai $\mathrm{Li}^{2}$, Jing $\mathrm{Li}^{2}$, Wenchao Han ${ }^{1,3}$, Chuanyang Shen ${ }^{2,4}$, Wangshu Tan ${ }^{2}$, \\ Jing Wei ${ }^{1,3}$, and Jianping Guo ${ }^{5}$ \\ ${ }^{1}$ Department of Atmospheric and Oceanic Sciences \& ESSIC, University of Maryland, College Park, Maryland 20740, USA \\ ${ }^{2}$ Department of Atmospheric and Oceanic Sciences, Peking University, Beijing 100871, China \\ ${ }^{3}$ State Key Laboratory of Remote Sensing Science and College of Global Change and Earth System Science, \\ Beijing Normal University, Beijing 100875, China \\ ${ }^{4}$ Department of Earth, Atmospheric and Planetary Sciences, Massachusetts Institute of Technology, Cambridge, MA, USA \\ ${ }^{5}$ State Key Laboratory of Severe Weather, Chinese Academy of Meteorological Sciences, Beijing 100081, China
}

Correspondence: Zhanqing Li (zli@atmos.umd.edu)

Received: 26 August 2019 - Discussion started: 30 September 2019

Revised: 11 January 2020 - Accepted: 13 February 2020 - Published: 27 March 2020

\begin{abstract}
The aerosol-planetary boundary layer (PBL) interaction was proposed as an important mechanism to stabilize the atmosphere and exacerbate surface air pollution. Despite the tremendous progress made in understanding this process, its magnitude and significance still have large uncertainties and vary largely with aerosol distribution and meteorological conditions. In this study, we focus on the role of aerosol vertical distribution in thermodynamic stability and PBL development by jointly using micropulse lidar, sun photometer, and radiosonde measurements taken in Beijing. Despite the complexity of aerosol vertical distributions, cloudfree aerosol structures can be largely classified into three types: well-mixed, decreasing with height, and inverse structures. The aerosol-PBL relationship and diurnal cycles of the PBL height and $\mathrm{PM}_{2.5}$ associated with these different aerosol vertical structures show distinct characteristics. The vertical distribution of aerosol radiative forcing differs drastically among the three types, with strong heating in the lower, middle, and upper PBL, respectively. Such a discrepancy in the heating rate affects the atmospheric buoyancy and stability differently in the three distinct aerosol structures. Absorbing aerosols have a weaker effect of stabilizing the lower atmosphere under the decreasing structure than under the inverse structure. As a result, the aerosol-PBL interaction can be strengthened by the inverse aerosol structure and can be po-
\end{abstract}

tentially neutralized by the decreasing structure. Moreover, aerosols can both enhance and suppress PBL stability, leading to both positive and negative feedback loops. This study attempts to improve our understanding of the aerosol-PBL interaction, showing the importance of the observational constraint of aerosol vertical distribution for simulating this interaction and consequent feedbacks.

\section{Introduction}

Aerosols have a critical impact on the earth's climate through aerosol-cloud interactions (ACIs) and aerosol-radiation interactions (ARIs). They also continue to contribute to the considerable uncertainty in quantifying and interpreting the earth's changing radiation budget and hydrological cycles (Charlson et al., 1992; Ackerman et al., 2004; Boucher et al., 2013; Li et al., 2011, 2017a; Guo et al., 2017, 2019a). Despite the great advances made in the past decades in observational and modeling studies of aerosol effects, it is still a challenge to accurately quantify aerosol effects on the climate system due to an inadequate understanding of some mechanisms and strong variations in aerosol type, loading, and vertical distribution (Haywood and Boucher, 2000; Jacobson, 2001; Carslaw et al., 2013; Huang et al., 2015; Guo et al., 2016a; 
Z. Li et al., 2016; Wei et al., 2019a, b). Aerosols can interact with thermodynamic stability through ARI (Atwater, 1971; Bond et al., 2013). Absorbing aerosols can stabilize the atmosphere (Ramanathan et al., 2001; Wang et al., 2013; Ding et al., 2016) and may also enhance convection and precipitation under certain conditions (Menon et al., 2002; Li et al., 2017b).

Thermodynamic stability in the planetary boundary layer (PBL) dictates the PBL development (Stull, 1988; W. Zhang et al., 2018), thereby dominating the vertical dissipation of surface pollutants to some degree. Aerosols, in turn, have important feedbacks on the stability in the PBL, depending on aerosol properties, especially those of light-absorbing aerosols (e.g., black, organic, and brown carbon). However, due to large uncertainties in aerosol radiative forcing, it remains a challenge to quantify the impact of aerosols on thermodynamic stability and PBL development. Conventionally, increasing the aerosol absorption tends to stabilize the atmosphere, leading to a reduced PBL height (PBLH). A more stable atmosphere and lower PBLH will, in turn, increase the surface aerosol loading, which is the well-established positive feedback loop in the aerosol-PBL interaction (e.g., Wang et al., 2015; Ding et al., 2016; Petäjä et al., 2016; Dong et al., 2017; Zou et al., 2017; Q. Huang et al., 2018; Z. Wang et al., 2018; Wang et al., 2019). However, such a positive feedback loop may not be real for all situations and is subject to confounding factors such as aerosol type, aerosol vertical distribution, soil moisture, and PBL regime (Guo et al., 2019b; Lou et al., 2019). Geiß et al. (2017) reported the ambiguous relationship between surface aerosol loading and PBLH, while our previous study revealed weak correlations between surface pollutants and the PBLH in mountainous or clean regions (Su et al., 2018). Lou et al. (2019) showed that aerosols have a positive correlation with the PBLH under stable PBL conditions, indicating the importance of thermodynamic conditions in the PBL.

Among others, numerical models are one of the viable methods used to determine aerosol impacts on stability and PBL (e.g., Wang et al., 2014; Ding et al., 2016; Y. Wang et al., 2018; Zhou et al., 2018). The aerosol optical depth (AOD), a measure of aerosol columnar loading, is usually taken into account in model simulations. However, the aerosol vertical distribution in models is generally prescribed and may differ greatly from the real situation. With observational constraints, the role of aerosol vertical distributions in aerosolPBL interactions warrants further investigation.

Ample observational datasets for Beijing are available, including aerosol vertical distributions derived from lidar, optical properties derived from the sun photometer, profiles of meteorological variables from radiosonde (RS), and surface $\mathrm{PM}_{2.5}$ and meteorological parameters. Based on these measurements, a radiative transfer model is used to simulate the vertical profiles of aerosol radiative forcing that are employed to investigate the impact of aerosols on buoyancy in the lower atmosphere.
The paper is structured as follows. Section 2 introduces the datasets and methods used. Section 3 presents analyses of aerosol-PBL interactions under different aerosol vertical structures. Section 4 discusses the results with a brief summary.

\section{Data and methods}

\subsection{Site description}

We utilized data from multiple sources in Beijing, a megacity located in the North China Plain. As one of the most densely populated and urbanized regions in the world, Beijing is a polluted region with high concentrations of absorbing aerosols (Zhang et al., 2019). The micropulse lidar (MPL) located in Beijing was operated continuously by Peking University $\left(39.99^{\circ} \mathrm{N}, 116.31^{\circ} \mathrm{E}\right)$ from March 2016 to December 2018, with a temporal resolution of $15 \mathrm{~s}$ and a vertical resolution of $15 \mathrm{~m}$. Due to incomplete laser pulse corrections, the near-surface lidar blind zone is $\sim 0.15 \mathrm{~km}$. Background subtraction, saturation, after-pulse, overlap, and range corrections are applied to raw MPL data to calculate the normalized signals (Yang et al., 2013; Su et al., 2017a). MPL data on rainy days are excluded. Level 1.5 AOD and single-scattering albedos (SSAs) are employed at multiple wavelengths (i.e., 0.44, 0.5, 0.67, 0.87, and $1.02 \mu \mathrm{m}$ ) from the Beijing_RADI $\left(40^{\circ} \mathrm{N}, 116.38^{\circ} \mathrm{E}\right)$ Aerosol Robotic Network (AERONET) site from 2011 to 2018 under cloud-free conditions (Holben et al., 1998; Smirnov et al., 2000; Zhang et al., 2017). The RS station $\left(39.80^{\circ} \mathrm{N}, 116.47^{\circ} \mathrm{E}\right)$ in Beijing, operated by the China Meteorological Administration, is $\sim 25 \mathrm{~km}$ from the MPL site. The variables observed at the RS station include meteorological data and profiles of water vapor, temperature, pressure, and wind. The vertical resolution of the RS is altitude dependent and generally less than $8 \mathrm{~m}$ (Guo et al., 2016b; W. Zhang et al., 2018). The RS is routinely launched at 08:00 local time (LT) and 20:00 LT each day and is also launched at 14:00 LT in the summer (June-July-August). RS measurements were collected during 2011-2018. To reduce small-scale biases and to obtain a picture of the regional variation in particulate matter with a diameter smaller than $2.5 \mu \mathrm{m}\left(\mathrm{PM}_{2.5}\right)$, we acquire mean $\mathrm{PM}_{2.5}$ data from 20 environmental monitoring stations located within $20 \mathrm{~km}$ from the lidar site, including one station at the Beijing Embassy of the United States. Figure 1 shows the topography of Beijing. The green square indicates the MPL site, and the yellow triangle indicates the AERONET station. The brown star represents the RS station, and the red-pink dots represent the $\mathrm{PM}_{2.5}$ sites.

\subsection{Statistical analysis methods}

The statistical significance is tested by two independent statistical methods, namely least-squares regression and the Mann-Kendall (MK) tau test (Mann, 1945; Kendall, 1975; J. 


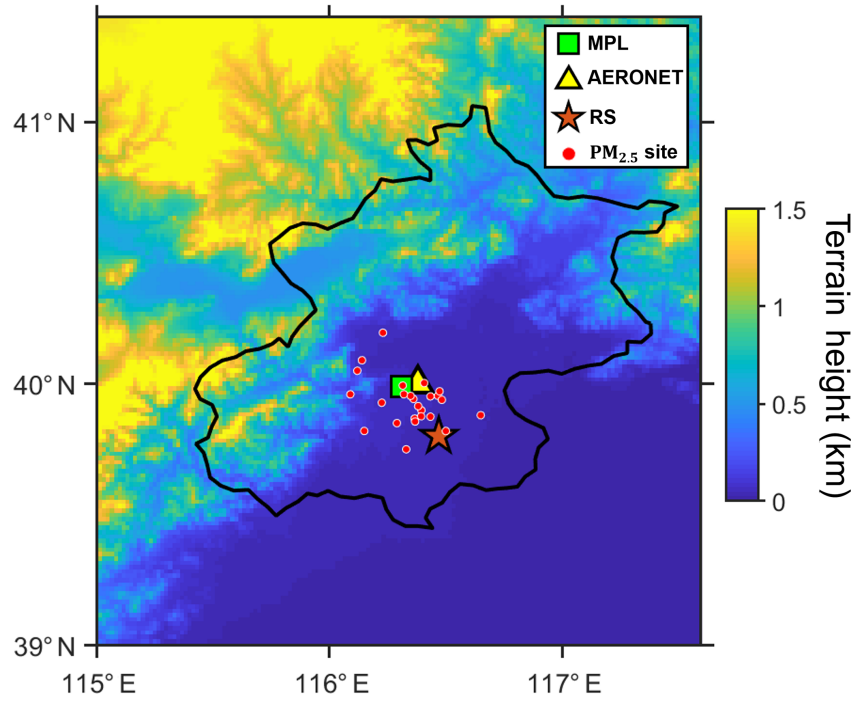

Figure 1. Topography of Beijing. The green square indicates the MPL site, and the yellow triangle indicates the AERONET station. The brown star shows the radiosonde (RS) station, and the red-pink dots show the $\mathrm{PM}_{2.5}$ sites.

$\mathrm{Li}$ et al., 2016). Least-squares regression typically assumes a Gaussian data distribution in the trend analysis, whereas the MK test is a nonparametric test without any assumed functional form. The latter is more suitable for data that do not follow a certain distribution. To improve the robustness of the analysis, a relationship is considered significant when the confidence level is above $99 \%$ for both the least-squares regression and the MK test. Hereafter, "significant" indicates that the correlation is statistically significant at the $99 \%$ confidence level.

We primarily use the linear-fit method to build relationships between different parameters. The Pearson correlation coefficient derived from the linear regression analysis measures the degree to which the data fit a linear relationship. However, following our recent work (Su et al., 2018), inverse fitting $[f(x)=A / x+B]$ is used to establish the relationship between PBLH and $\mathrm{PM}_{2.5}$. The magnitude of the correlation coefficient $\left(R^{\dagger}\right)$ is designed to measure the degree to which the data fit an inverse relationship. Since the relationship between the PBLH and $\mathrm{PM}_{2.5}$ is nonlinear, the inverse fitting better characterizes this relationship.

\subsection{PBLH and buoyancy derived from RS}

The RS vertical resolution varies according to the balloon ascending rate. The RS records measurements every $1.2 \mathrm{~s}$, which represents an approximate vertical resolution of 5$8 \mathrm{~m}$. Prior to the retrieval of the PBLH, we further resample RS data to achieve a vertical resolution of $5 \mathrm{hPa}$ with linear interpolation. We follow a well-established method developed by Liu and Liang (2010) to derive the PBLH based on profiles of the potential temperature gradient that takes into account different stability conditions. In this study, we only focus on PBLs driven by buoyancy, so PBLs driven by low-level jets are excluded using RS-derived wind profiles (Liu and Liang, 2010; Miao et al., 2018).

The static stability of the atmosphere is determined by the buoyancy force, which is expressed as (Wallace and Hobbs, 2006)

$B=\frac{d^{2} z}{\mathrm{~d} t^{2}}=\frac{T^{\prime}-T}{T} g=-g \Delta z \frac{1}{\theta} \frac{\mathrm{d} \theta}{\mathrm{d} z}$,

where $z$ is the height of the air parcel, and $t$ indicates the time. $T^{\prime}$ represents the temperature of the parcel, $T$ represents the temperature of the environment, and $\theta$ is the virtual potential temperature of the environment. An atmospheric layer is convective if the buoyancy is above zero and stable when the buoyancy is below zero. If the buoyancy is near zero, the atmosphere is neutral. We calculated buoyancy with a vertical resolution of $15 \mathrm{~m}$. Based on the identification method for PBL type (Liu and Liang, 2010; W. Zhang et al., 2018), we present profiles of buoyancy forcing for stable, neutral, and convective PBLs (Fig. 2a). The results shown are averages from 3069 radiosonde measurements, of which 438 cases are convective PBLs, 714 cases are neutral PBLs, and 1916 cases are stable PBLs. The strongest upward or downward forcing occurs near the surface. Figure $2 \mathrm{~b}-\mathrm{c}$ further show the height-dependent correlation coefficients between buoyancy and PBLH-PM 2.5 with an interpolation window of $0.2 \mathrm{~km}$. Note that the PBLH and surface $\mathrm{PM}_{2.5}$ are fixed for the entire column, and the buoyancy is height dependent. Due to the insufficient development of the PBL, we do not use RS data at 08:00 LT here. To exclude the impact induced by the dragging effects of rainfall, we only consider cases without precipitation within the past $24 \mathrm{~h}$. Strong upward buoyancy can uplift the PBLH and mitigate surface pollutants, especially in the lower atmosphere. Thus, we vertically average the buoyancy forcing profiles within the lowest $1 \mathrm{~km}$ (red line in Fig. 2b-c), defined as the lower atmosphere buoyancy (LAB). As shown in Fig. 3a-b, LAB and $\mathrm{PM}_{2.5}$ are negatively correlated, and LAB and PBLH are positively correlated. LAB also has a significant negative correlation with absorbing aerosol optical depth (Fig. 3c). This may be due to the stabilizing effect of absorbing aerosols on the atmosphere, which is widely reported in many previous studies (H. Wang et al., 2015; Ding et al., 2016; Petäjä et al., 2016; Dong et al., 2017; Li et al., 2017b; X. Huang et al., 2018).

\subsection{PBLH and aerosol extinction coefficient derived from MPL}

MPL data from Beijing were used to retrieve the PBLH during the daytime (08:00-19:00 LT). Many methods have been developed for retrieving the PBLH from MPL measurements, e.g., the signal threshold (Melfi et al., 1985), the maximum of the signal variance (Hooper and Eloranta, 1986), the minimum of the signal profile derivative (Flamant et al., 1997), 

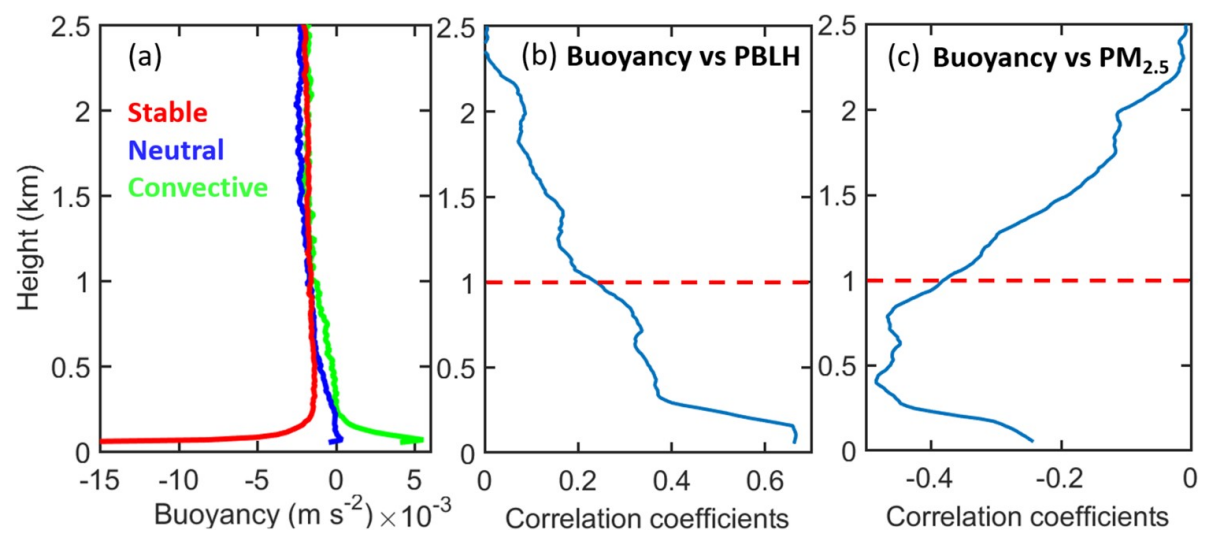

Figure 2. (a) Averaged vertical profiles of buoyancy forcing in stable, neutral, and convective PBLs. (b) Height-dependent correlation coefficients between buoyancy and PBLH. (c) Height-dependent correlation coefficients between buoyancy and surface PM 2.5 . Note that the PBLH and surface $\mathrm{PM}_{2.5}$ are fixed for the entire column, and the buoyancy is height dependent. The buoyancy in the lower atmosphere $(<1 \mathrm{~km})$ has the most important impact on the PBLH and surface $\mathrm{PM}_{2.5}$. The buoyancy and PBLH are calculated from RS measurements made at 14:00 LT and 20:00 LT from 2011 to 2018.

and the wavelet transform (Cohn and Angevine, 2000; Davis et al., 2000; Su et al., 2017b; Chu et al., 2019). To derive the PBLH from MPL data, we adopted previous wellestablished approaches with several refinements, which have already been validated by long-term data collected at the Southern Great Plains site (Sawyer and Li, 2013; Su et al., 2020).

We initially identify the local maximum positions (range: $0.25-4 \mathrm{~km}$ ) in the covariance transform function collocated with a signal gradient larger than a certain threshold. We further estimated the shot noise $(\sigma)$ induced by background light and dark currents for each profile, and then set the threshold as $3 \sigma$. The initial PBLH retrieval (at 08:00 LT) is constrained by the PBLH value derived from the morning RS sounding. Then, the following PBLHs are retrieved using a stabilitydependent model based on continuity. Boundary layer clouds are identified to diagnose the PBLH for cloudy cases. Figure $3 \mathrm{~d}$ presents the comparison of summertime PBLH results derived from MPL and RS at 14:00 LT, showing good agreement $(R=0.79)$.

Multiple studies have provided a well-established algorithm to retrieve the vertical profiles of the aerosol extinction coefficient (AEC) from MPL data (e.g., Fernald, 1984; Klett, 1985; Liu et al., 2012). The Klett method is further used to retrieve extinction profiles (Klett, 1985). The columnaveraged extinction-to-backscatter ratio (the so-called lidar ratio) is an important parameter in the retrieval process and is constrained using AERONET-derived AOD at $0.5 \mu \mathrm{m}$. The $\mathrm{AEC}$ is assumed to be equal within the blind zone. The overall uncertainties from the overlap function, the lidar ratio, the effects of multiple scattering, and noise fall within the range of $20 \%-30 \%$ in the retrieval process (He et al., 2006).
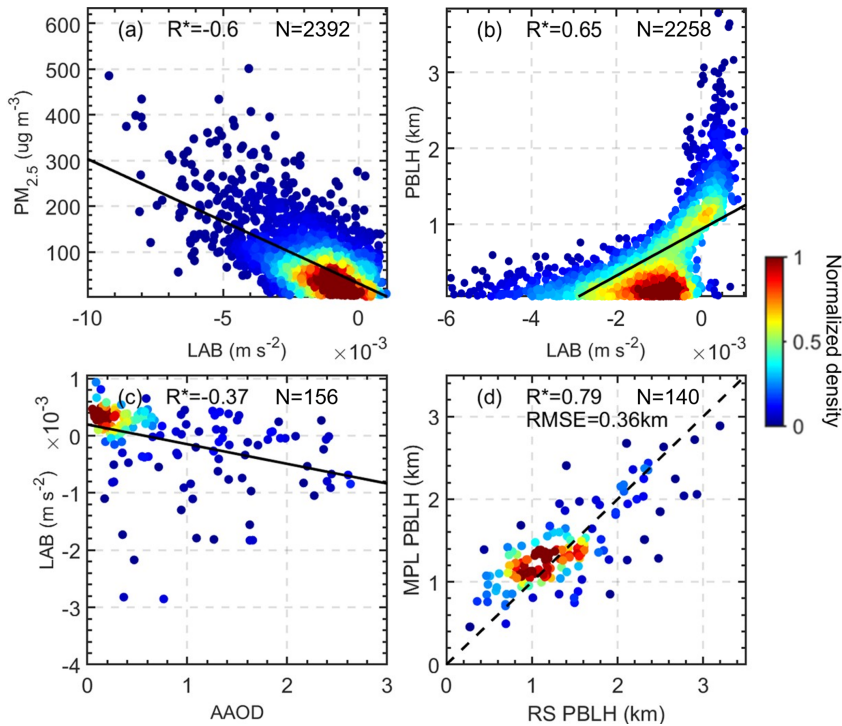

Figure 3. (a) The relationship between lower atmosphere buoyancy (LAB) and $\mathrm{PM}_{2.5}$. (b) The relationship between LAB and PBLH. (c) The relationship between absorbing aerosol optical depth (AAOD) and LAB. In (a), (b), and (c), the LAB and PBLH are derived from RS measurements made at 14:00 and 20:00 LT, and AAOD is derived from AERONET measurements. The black solid lines indicate the best-fit lines from linear regression. (d) Comparison of PBLHs derived from the MPL and RS at 14:00 LT. Each panel gives the correlation coefficients $(R)$, sample number $(N)$, and root mean square error (RMSE). $R$ with an asterisk indicates that the correlation is statistically significant at the $99 \%$ confidence level. The color-shaded dots indicate the normalized sample density.

\subsection{Estimation of the impacts of aerosols on buoyancy}

To show vertical profiles of aerosol radiative forcing, the Santa Barbara DISORT Atmospheric Radiative Transfer 

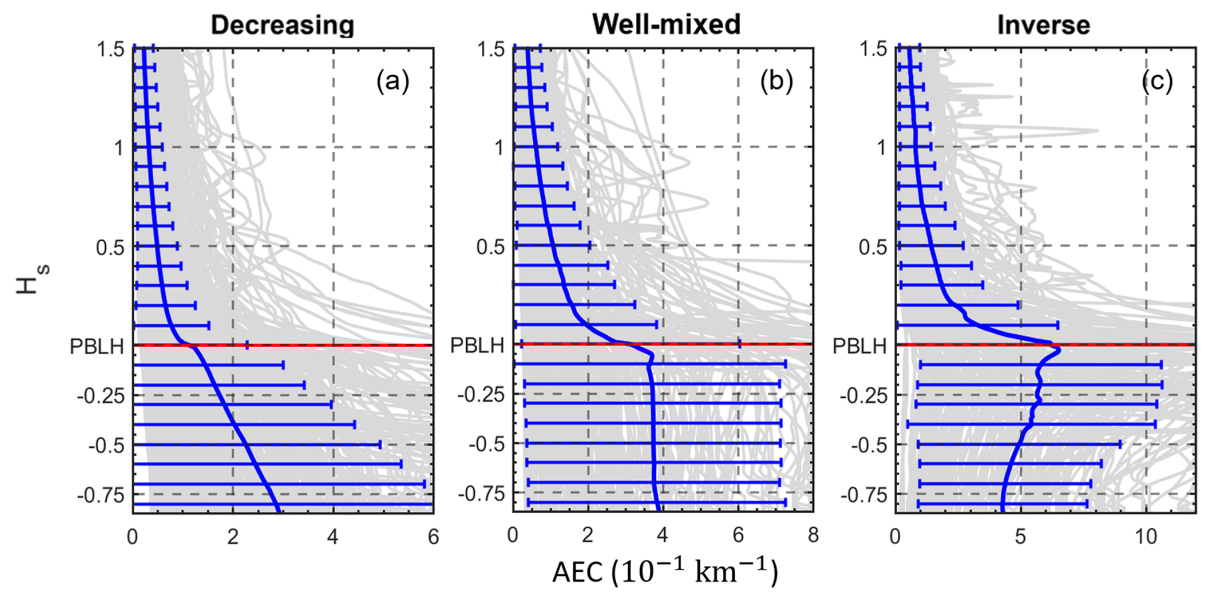

Figure 4. Normalized vertical profiles of the aerosol extinction coefficient (AEC) for (a) decreasing, (b) well-mixed, and (c) increasing (i.e., inverse) aerosol structures. The red line marks the position of the PBLH, the solid blue lines represent the average profiles of corresponding profiles, and error bars represent the standard deviations.
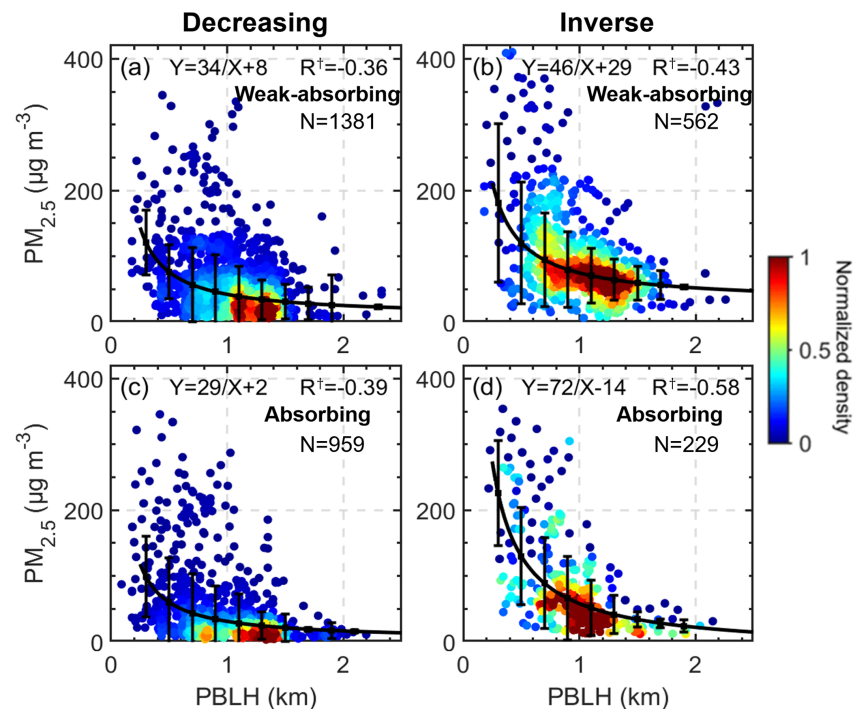

Figure 5. The relationship between MPL-derived PBLH and $\mathrm{PM}_{2.5}$ for (a) weakly absorbing and (c) absorbing aerosols for the decreasing aerosol structure. The relationship between MPL-derived PBLH and $\mathrm{PM}_{2.5}$ for (b) weakly absorbing and (d) absorbing aerosols for the increasing (i.e., inverse) aerosol structure. Black lines represent the inverse fits, and the whiskers indicate the standard deviations. The fitting functions and number of samples are given in each panel, along with the correlation coefficient $\left(R^{\dagger}\right)$ for the inverse fit.

(SBDART) model (Ricchiazzi et al., 1998) was used to simulate the atmospheric heating rate $(\mathrm{d} T / \mathrm{d} t)$ induced by aerosols (Liu et al., 2012; Dong et al., 2017). Integrated aerosol inputs include AODs, SSAs (i.e., at 0.44, 0.67, 0.87, and $1.02 \mu \mathrm{m})$ retrieved from AERONET measurements, and AEC profiles at $0.5 \mu \mathrm{m}$ obtained from the MPL. We also use Moderate Resolution Imaging Spectroradiometer surface reflectances as an additional input (https://modis.gsfc.nasa. gov/data/dataprod/mod09.php, last access: April 2019). We further use heating rates induced by aerosols to estimate the impact of aerosols on buoyancy.

Theoretically, the rate of change in buoyancy for a certain layer is expressed as

$$
\begin{aligned}
& \frac{\mathrm{d} B}{\mathrm{~d} t}=\frac{d}{\mathrm{~d} t}\left(\frac{T_{0}-\Gamma_{\mathrm{d}} \Delta z-T}{T} g\right)= \\
& \frac{\left(\frac{\mathrm{d} T_{0}}{\mathrm{~d} t}-\frac{\mathrm{d} T}{\mathrm{~d} t}\right) T+\frac{\mathrm{d} T}{\mathrm{~d} t}\left(\Gamma_{\mathrm{d}}-\Gamma\right) \Delta z}{T^{2}} g,
\end{aligned}
$$

where most parameters are defined in the same way as in Eq. (1), and $\Gamma_{\mathrm{d}}(\Gamma)$ represents the dry adiabatic lapse rate (environmental lapse rate). We primarily focus on the rate of change in buoyancy during the noontime period (11:0015:00 LT), when the PBL is well-developed and aerosol radiative forcing is strong. The rate of change in buoyancy $(\mathrm{d} B / \mathrm{d} t)$ induced by aerosols is largely determined by the aerosol heating rate, which can be produced by the radiative transfer model. Additional inputs include the environmental lapse rate and temperature obtained from noontime RS soundings in the summer. For other times, the environmental lapse rate and temperature are obtained from MERRA-2 reanalysis data, which assimilate coarse-resolution RS observations (Rienecker et al., 2011). In this way, we can estimate $\mathrm{d} B / \mathrm{d} t$ induced by aerosols with a primary focus on the daytime. Note that the errors in MERRA-2 data lead to uncertainties in the estimated $\mathrm{d} B / \mathrm{d} t$. A $1-3 \mathrm{~K}$ uncertainty in MERRA-2 temperatures (Gelaro et al., 2017) leads to $1 \%$ $3 \%$ relative biases in the estimated $\mathrm{d} B / \mathrm{d} t$. Considering the large variation in $\mathrm{d} B / \mathrm{d} t$ for different aerosol structures, the biases resulting from MERRA-2 data are not a serious issue. 

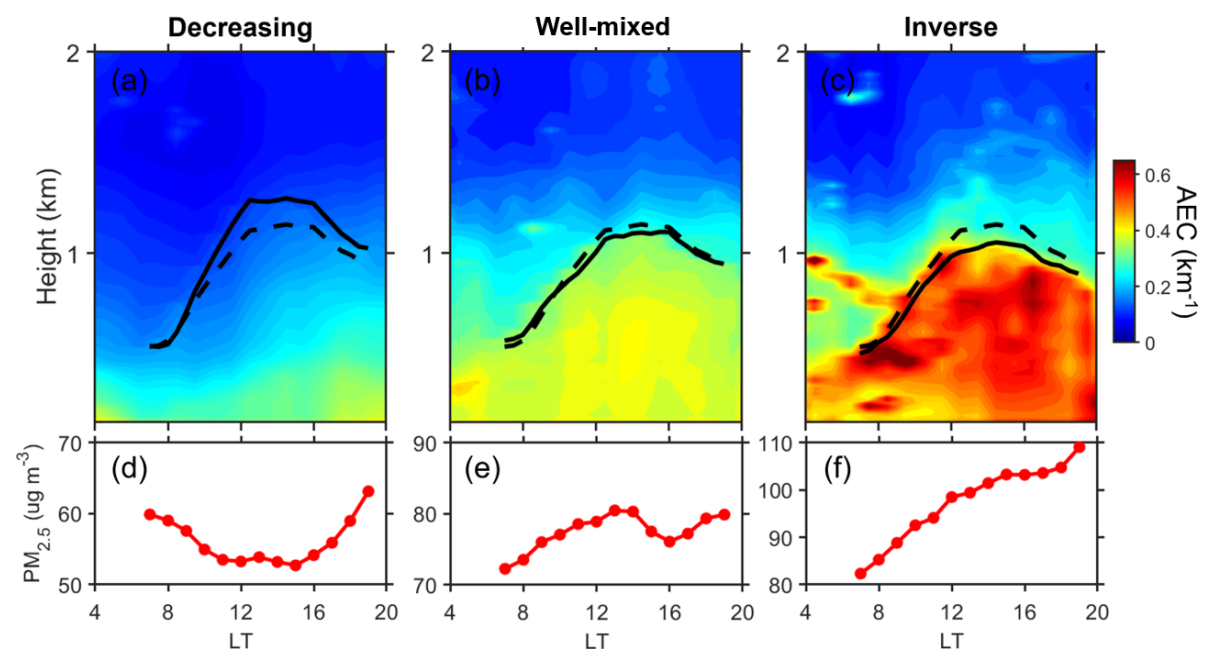

Figure 6. The averaged diurnal variations in AEC for (a) decreasing, (b) well-mixed, and (c) increasing (i.e., inverse) aerosol structures. Solid black lines indicate the averaged diurnal cycles of MPL-derived PBLH under the different aerosol structures. Dashed black lines represent the mean MPL-derived PBLH diurnal cycles. (d, e, f) The averaged diurnal variations in surface $\mathrm{PM}_{2.5}$ under the different aerosol structures.
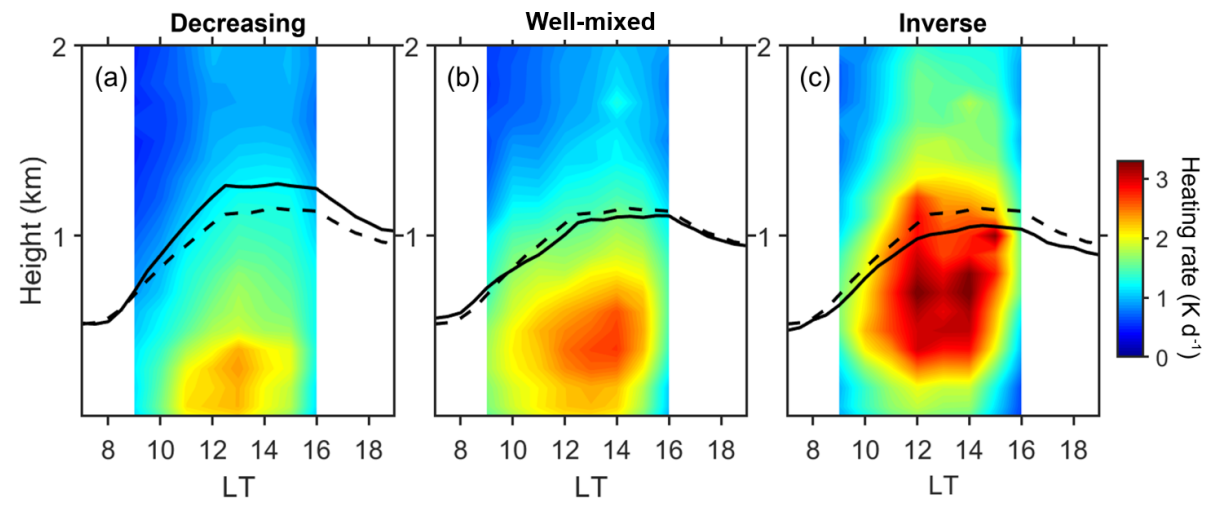

Figure 7. The averaged diurnal variations in aerosol radiative forcing in the vertical for (a) decreasing, (b) well-mixed, and (c) increasing (i.e., inverse) structures of aerosol loading. Solid black lines indicate the mean diurnal cycles of MPL-derived PBLH under different aerosol structures. Dashed black lines represent the mean MPL-derived PBLH diurnal cycles.

\section{Results}

\subsection{Classification of different aerosol structure scenarios}

By altering the adiabatic heating rate of the atmosphere, the aerosol vertical distribution is of great importance to the PBL. Based on cloud-free AEC profiles in the PBL, aerosol vertical structures can be classified into three types: wellmixed, decreasing with height, and its inverse, increasing with height. If AEC varies by less than $20 \%$ within the lowest $80 \%$ of the PBL, it is considered a well-mixed structure. For the other cases, a decreasing structure indicates a peak in AEC near the surface, and the inverse structure indicates a peak in AEC in the middle or upper PBL.

To investigate the vertical variation in AEC within the PBL, the evolution of the PBLH has to be taken into account.
Following previous studies (Ferrero et al., 2014; Kuang et al., 2016), vertical profiles were normalized by introducing a standardized height $\left(H_{\mathrm{s}}\right)$, calculated as follows:

$H_{\mathrm{s}}=\frac{z-\mathrm{PBLH}}{\text { PBLH }}$,

where $z$ is the height above the ground, and $H_{\mathrm{S}}$ is 0 at the PBL top and -1 at ground level. Figure 4 shows the normalized vertical profiles of AEC derived from MPL data for different aerosol structures around noontime. The number of samples and percentages of decreasing, well-mixed, and increasing aerosol structures are 998 (51\%), 611 (32\%), and 330 $(17 \%)$, respectively. Since a temperature inversion located at the PBL top traps moisture and aerosols, there is a sharp decrease in the AEC profile from the PBL upper boundary to the free atmosphere. Variations in the aerosol vertical distribution largely depend on different conditions but share similar features among the different aerosol structure patterns. 


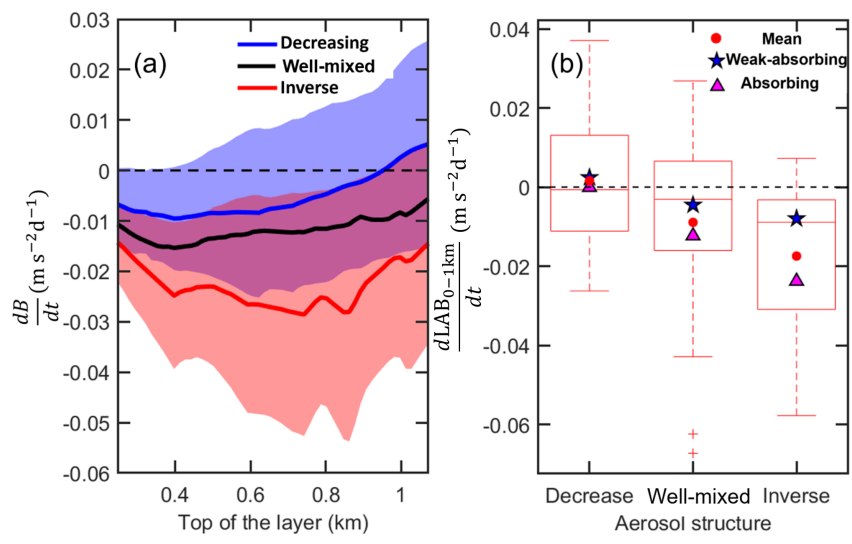

Figure 8. (a) The rate of change in buoyancy $(\mathrm{dB} / \mathrm{dt})$ in a layer of the lowest atmosphere for decreasing (blue), well-mixed (black), and inverse (red) aerosol structures during noontime. The bottom of the layer is the surface, and the rate of change in buoyancy is subjected to the top of the layer. The shaded areas show the standard deviations of the rate of change in buoyancy. (b) Box-and-whisker plots showing the 10th, 25th, 50th, 75th, and 90th percentile values of the rate of change in $\mathrm{LAB}_{0-1 \mathrm{~km}}$ (integrated buoyancy within the lowest $1 \mathrm{~km}$ ) during noontime. Red dots indicate the mean values, and blue stars and pink triangles show the means for weakly absorbing (SSA $>0.9)$ and absorbing (SSA < 0.85) cases.

Despite complex aerosol vertical distributions, these three types of profiles can account for most of the cloud-free cases.

\subsection{BLH and $\mathbf{P M}_{2.5}$ under different aerosol structure scenarios}

Absorbing aerosols tend to have a positive feedback with the PBLH, and the aerosol vertical distribution plays a critical role in this process. We investigate the relationship between MPL-derived PBLH and $\mathrm{PM}_{2.5}$ for absorbing (daily average SSA $\leq 0.85$ ) or weakly absorbing (daily average SSA >0.9) aerosols for increasing and decreasing aerosol structures during 09:00-19:00 LT (Fig. 5). The PBLH-PM 2.5 relationships can represent the intensity of the aerosol-PBL interaction. In general, there are stronger correlations between PBLH and $\mathrm{PM}_{2.5}$ for the inverse aerosol structure. This is likely caused by substantial heating in the upper PBL, facilitating the formation of a temperature inversion and further increasing the stability of the PBL. For the decreasing aerosol structure, aerosols may not significantly redistribute adiabatic energy. Hence, the PBLH-PM 2.5 correlation is relatively weak. Significant PBLH-PM 2.5 correlations are found for both absorbing and weakly absorbing cases, indicating that scattering aerosols may also play an important role in the aerosol-PBL interaction, especially for the inverse aerosol structure.

Figure 6 presents the averaged diurnal cycles of AEC, $\mathrm{PBLH}$, and $\mathrm{PM}_{2.5}$ for different aerosol vertical structures, classified based on the average AEC profiles during noontime. High humidity cases (surface relative humidity >
$90 \%$ ) and strong wind cases (wind speed $>5 \mathrm{~m} \mathrm{~s}^{-1}$ ) are excluded. Here, both AEC and PBLH are derived from MPL data. Data are collected on 371 available days, of which 191 have decreasing aerosol structures, 122 have well-mixed aerosol structures, and 58 have inverse aerosol structures. Multiple entangled factors can contribute to the formation of different aerosol structures within the PBL, including synoptic patterns, new particle formation, vertical turbulence, horizontal transport, and entrainment rates to name a few. In general, the inverse structure is characterized by higher aerosol loadings and lower PBLHs, whereas the decreasing structure is characterized by light pollution and a well-developed PBL. In theory, $\mathrm{PM}_{2.5}$ should generally decrease with increasing PBLH in the morning due to the dilution effect. This situation is demonstrated clearly for decreasing aerosol structures. However, $\mathrm{PM}_{2.5}$ continuously grows during the daytime when an inverse aerosol structure is present, regardless of the PBLH diurnal cycle. Even though many factors control the diurnal variations in aerosols and the PBL, the strong aerosol-stability interaction generates an unfavorable condition for the vertical dissipation of aerosols, so the surface aerosol loading can continuously accumulate due to emissions.

The correlations and statistical results concerning the PBLH and $\mathrm{PM}_{2.5}$ provide hints about the differences in aerosol-PBL interactions for different aerosol structures. However, these results cannot explain the feedback loop and causality. Therefore, we further use the SBDART model with the constraint of ample observations to investigate the vertical profiles of radiative forcing induced by aerosols and its impacts on atmospheric stability.

\subsection{Aerosol radiative forcing for different aerosol structures}

Following the description in Sect. 2.5, we calculate the statistical means of aerosol radiative forcing in the vertical for decreasing, well-mixed, and inverse aerosol structures derived from the cases presented in Fig. 6. Figure 7 shows that the vertical distributions of the heating rate differ drastically among the different aerosol structures. For the inverse aerosol structure scenario, aerosols cause substantial heating in the upper PBL, facilitating the formation of a temperature inversion and further increasing the stability in the PBL. For the decreasing aerosol structure scenario, the abundance of aerosols at the bottom of PBL heats the lower PBL so can potentially enhance convection in the PBL.

There are considerable differences in the heating rate among the three distinct aerosol structures (Fig. 8), which affects the atmospheric buoyancy and stability differently. On average, aerosols generally suppress buoyancy in the lower atmosphere. Such an effect is quite notable for the inverse structure and is insignificant for the decreasing structure, with large standard deviations. Absorbing aerosols are not very helpful for stabilizing the lower atmosphere when 


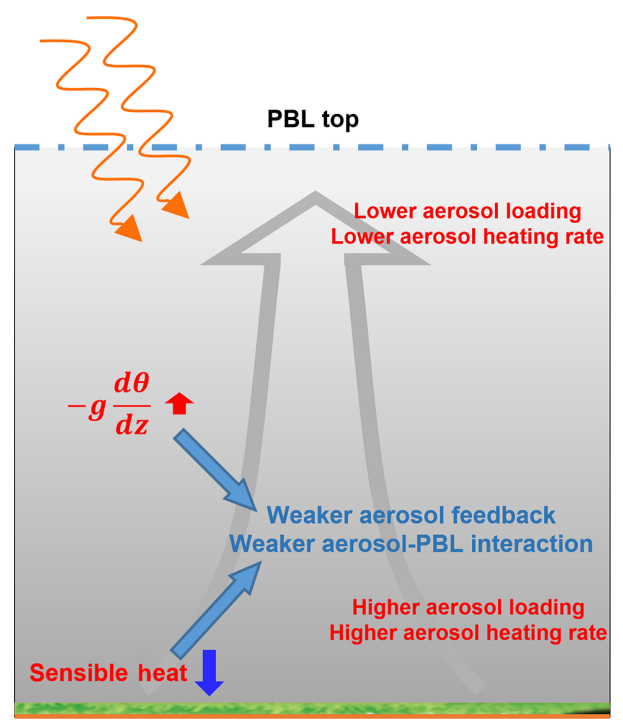

Decreasing structure

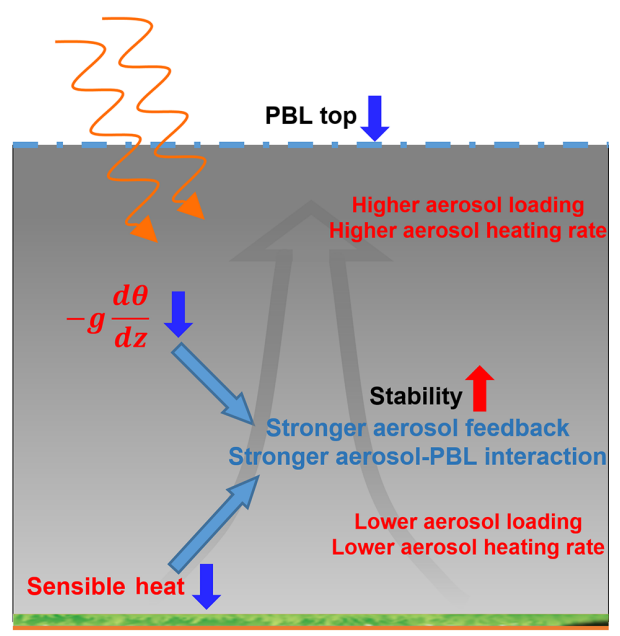

Inverse structure

Figure 9. Schematic diagrams describing aerosol-PBL interactions when decreasing and inverse aerosol structures are present. The blue dash-dotted line indicates the top of the PBL. Orange curved arrows indicate solar radiation. The background grey arrow sketches the vertical transport of humidity, aerosols, and heat. The background greyscale indicates the pollution level.

a decreasing aerosol structure is present, but they play an important role when an inverse aerosol structure is present. As such, we expect the strongest aerosol-PBL interaction to occur for absorbing aerosol cases when an inverse aerosol structure is present, consistent with the results shown in Fig. 5.

Figure 9 shows schematic diagrams of the interactions between aerosols, stability, and the PBL when decreasing or inverse aerosol structures are present. Overall, both decreasing and inverse aerosol structures can cool the surface and suppress sensible heat, thus stabilizing the PBL. In both cases, aerosols have notable stabilizing effects near the surface.

When a decreasing aerosol structure is present, abundant aerosols near the surface generate a stronger aerosol heating rate in the lower PBL than in the upper PBL. Such aerosol radiative forcing lowers the potential temperature gradient $(\mathrm{d} \theta / \mathrm{d} z)$ in the middle and upper PBL and can further strengthen vertical convection in the middle and upper PBL. The opposite aerosol effects on PBL stability lead to a relatively weak aerosol feedback and a relatively weak aerosol-PBL interaction. When an inverse aerosol structure is present, the significant heating effect on the upper PBL facilitates the formation of temperature inversion and further increases the stability and suppresses the PBLH. The notable increase in stability leads to the strong, positive aerosol feedback.

Highly variable aerosol vertical distributions cause large variations in the impact of aerosol on stability and thus exert important and highly variable influences on the aerosolPBL interactions. Although aerosol stabilizes the PBL for the majority of cases, aerosol can also suppress stability in the lower atmosphere, when the aerosol heating effect is much stronger on the near surface than the upper PBL, and further lead to a potential negative feedback loop. The positive feedback loop leads to strong aerosol-PBL interactions, whereas the negative feedback loop leads to weak aerosol-PBL interactions. It explains the paradox of the different correlations between PBLH and surface pollutants since its magnitude, significance, and even sign reportedly vary or even reverse (Quan et al., 2013; Tang et al., 2016; Geiß et al., 2017; Su et al., 2018).

\section{Summary and discussion}

Based on integrated aerosol and meteorological measurements made in Beijing, the aerosol-PBL interaction is assessed for different aerosol vertical structures, i.e., decreasing, well-mixed, and inversely increasing with height. The aerosol-PBL relationships and the diurnal cycles of PBLH and $\mathrm{PM}_{2.5}$ show distinct characteristics among the different aerosol vertical patterns. For the decreasing aerosol structure, $\mathrm{PM}_{2.5}$ decreases in the morning with relatively large PBLH growth rates. In this situation, absorbing aerosols are not very helpful in stabilizing the lower atmosphere. For the inverse aerosol structure, $\mathrm{PM}_{2.5}$ continuously grows during the daytime with relatively low PBLH growth rates. This phenomenon could be a sign of a strong aerosol-PBL interaction. The aerosol radiative forcing in the vertical for decreasing, well-mixed, and inverse aerosol structures differ drastically, with strong heating in the lower, middle, and upper $\mathrm{PBL}$, respectively. Such a difference in the heating rate af- 
fects the atmospheric buoyancy and stability differently in the three distinct aerosol structures.

Turbulent fluxes and eddies in the PBL could spread out and redistribute the radiative effects induced by aerosols. $\mathrm{Nu}$ merical models are needed to quantify the aerosol-PBL interaction and consequent feedbacks (e.g., Y. Wang et al., 2013; Ding et al., 2016; Z. Wang et al., 2018; Zhou et al., 2018). Aerosol vertical distributions vary greatly on both temporal and vertical scales and critically affect aerosol radiative effects. However, the aerosol vertical distribution is still poorly represented in numerical models, partly due to a lack of observational constraints. This study reveals the important role of the aerosol vertical distribution in aerosol-PBL interactions, which should be carefully taken into account in both observational analyses and model simulations.

This study used column-averaged aerosol properties from AERONET. However, the vertical variations in SSA and aerosol type remain unknown, inducing uncertainties in the estimation of aerosol effects. In the future, we plan to use aircraft data from field campaigns to better account for the influence of different types of aerosols with different properties.

Data availability. Hourly $\mathrm{PM}_{2.5}$ data are released by the Ministry of Ecology and Environment of China (2020, http://106.37. 208.233:20035). MERRA-2 reanalysis data are publicly available at https://disc.gsfc.nasa.gov/datasets?keywords=_merra202\&page= 1 (NASA, 2019a). AERONET data are publicly available at https: //aeronet.gsfc.nasa.gov (NASA, 2019b). Meteorological data are provided by the data center of the China Meteorological Administration (http://data.cma.cn/en, China Meteorological Data Service Center, 2019). Other data used in this study are available upon the request from the lead author (tianning@umd.edu).

Author contributions. TS and ZL conceptualized this study. TS carried out the analysis with comments from other coauthors. CL, JL, and WT carried out the MPL observations. JG provided auxiliary data. WH, CS, WT, JW, and JG provided useful suggestions for the study. TS and ZL interpreted the data and wrote the paper with contributions from all coauthors.

Competing interests. The authors declare that they have no conflict of interest.

Acknowledgements. This study is supported by the National Key R\&D Program of China (2017YFC1501702) and National Natural Science Foundation of China (91544217). This study is also supported by the Department of Energy (DOE) Atmospheric System Research program (DE-SC0018996) and the National Science Foundation (AGS1837811). The authors would like to acknowledge Zhengqiang Li for his effort in establishing and maintaining the Beijing RADI AERONET site. We are grateful for the provision of $\mathrm{PM}_{2.5}$ data by the Ministry of Environmental Protection of the
People's Republic of China and also for the provision of meteorological and radiosonde data by the China Meteorological Administration. We extend our sincerest thanks to the MERRA team for their datasets.

Financial support. This research has been supported by the National Key R\&D Program of China (grant no. 2017YFC1501702), the National Natural Science Foundation of China (grant no. 91544217), the U.S. Department of Energy Atmospheric System Research program (grant no. DESC0018996), and the U.S. National Science Foundation (grant no. AGS1837811).

Review statement. This paper was edited by Aijun Ding and reviewed by two anonymous referees.

\section{References}

Ackerman, A. S., Kirkpatrick, M. P., Stevens, D. E., and Toon, O. B.: The impact of humidity above stratiform clouds on indirect aerosol climate forcing, Nature, 432, 1014-1017, https://doi.org/10.1038/nature03174, 2004.

Atwater, M. A.: The radiation budget for polluted layers of the urban environment, J. Appl. Meteorol., 10, 205-214, 1971.

Bond, T. C., Doherty, S. J., Fahey, D. W., Forster, P. M., Berntsen, T., DeAngelo, B. J., Flanner, M. G., Ghan, S., Kärcher, B., Koch, D., and Kinne, S.: Bounding the role of black carbon in the climate system: A scientific assessment, J. Geophys. Res.-Atmos., 118, 5380-5552, 2013.

Boucher, O., Randall, D., Artaxo, P., Bretherton, C., Feingold, G., Forster, P., Kerminen, V. M., Kondo, Y., Liao, H., Lohmann, U., and Rasch, P.: Clouds and aerosols, in: Climate Change 2013: The Physical Science Basis, Contribution of Working Group I to the Fifth Assessment Report of the Intergovernmental Panel on Climate Change, Cambridge Univ. Press, Cambridge, UK and New York, NY, USA, 571-657, 2013.

Carslaw, K. S., Lee, L. A., Reddington, C. L., Pringle, K. J., Rap, A., Forster, P. M., Mann, G. W., Spracklen, D. V., Woodhouse, M. T., Regayre, L. A., and Pierce, J. R.: Large contribution of natural aerosols to uncertainty in indirect forcing, Nature, 503 , p. 67, 2013.

Charlson, R. J., Schwartz, S. E., Hales, J. M., Cess, R. D., Coakley, J. J., Hansen, J. E., and Hofmann, D. J.: Climate forcing by anthropogenic aerosols, Science, 255, 423-430, 1992.

China Meteorological Data Service Center: Meteorological Data, available at: http://data.cma.cn/en, last access: April 2019.

Chu, Y., Li, J., Li, C., Tan, W., Su, T., and Li, J.: Seasonal and diurnal variability of planetary boundary layer height in Beijing: Intercomparison between MPL and WRF results, Atmos. Res., 227, 1-13, https://doi.org/10.1175/15200450(2000)039<1233:BLHAEZ>2.0.CO;2, 2019.

Cohn, S. A. and Angevine, W. M.: Boundary layer height and entrainment zone thickness measured by lidars and wind-profiling radars, J. Appl. Meteorol., 39, 1233-1247, 2000.

Davis, K. J., Gamage, N., Hagelberg, C. R., Kiemle, C., Lenschow, D. H., and Sullivan P. P.: An objective method for deriving atmospheric structure from airborne lidar observations. J. Atmos. 
Ocean. Tech., 17, 1455-1468, https://doi.org/10.1175/15200426(2000)017<1455:AOMFDA>2.0.CO;2, 2000.

Ding, A. J., Huang, X., Nie, W., Sun, J. N., Kerminen, V. M., Petäjä, T., Su, H., Cheng, Y. F., Yang, X. Q., Wang, M. H., and Chi, X. G.: Enhanced haze pollution by black carbon in megacities in China, Geophys. Res. Lett., 43, 2873-2879, 2016.

Dong, Z., Li, Z., Yu, X., Cribb, M., Li, X., and Dai, J.: Opposite long-term trends in aerosols between low and high altitudes: a testimony to the aerosol-PBL feedback, Atmos. Chem. Phys., 17, 7997-8009, https://doi.org/10.5194/acp-177997-2017, 2017.

Fernald, F. G.: Analysis of atmospheric lidar observations: some comments, Appl. Optics, 23, 652-653, 1984.

Ferrero, L., Castelli, M., Ferrini, B. S., Moscatelli, M., Perrone, M. G., Sangiorgi, G., D’Angelo, L., Rovelli, G., Moroni, B., Scardazza, F., Močnik, G., Bolzacchini, E., Petitta, M., and Cappelletti, D.: Impact of black carbon aerosol over Italian basin valleys: high-resolution measurements along vertical profiles, radiative forcing and heating rate, Atmos. Chem. Phys., 14, 96419664, https://doi.org/10.5194/acp-14-9641-2014, 2014.

Flamant, C., Pelon, J., Flamant, P. H., and Durand, P.: Lidar determination of the entrainment zone thickness at the top of the unstable marine atmospheric boundary layer, Bound.-Lay. Meteorol., 83, 247-284, 1997.

Geiß, A., Wiegner, M., Bonn, B., Schäfer, K., Forkel, R., von Schneidemesser, E., Münkel, C., Chan, K. L., and Nothard, R.: Mixing layer height as an indicator for urban air quality?, Atmos. Meas. Tech., 10, 2969-2988, https://doi.org/10.5194/amt10-2969-2017, 2017.

Gelaro, R., McCarty, W., Suárez, M. J., Todling, R., Molod, A., Takacs, L., Randles, C. A., Darmenov, A., Bosilovich, M. G., Reichle, R., and Wargan, K.: The modern-era retrospective analysis for research and applications, version 2 (MERRA-2), J. Climate, 30, 5419-5454, 2017.

Guo, J., Liu, H., Wang, F., Huang, J., Xia, F., Lou, M., Wu, Y., Jiang, J., Xie, T., Zhaxi, Y., and Yung, Y.: Three-dimensional structure of aerosol in China: A perspective from multi-satellite observations, Atmos. Res., 178-179, 580-589, 2016a.

Guo, J., Miao, Y., Zhang, Y., Liu, H., Li, Z., Zhang, W., He, J., Lou, M., Yan, Y., Bian, L., and Zhai, P.: The climatology of planetary boundary layer height in China derived from radiosonde and reanalysis data, Atmos. Chem. Phys., 16, 13309-13319, https://doi.org/10.5194/acp-16-13309-2016, $2016 \mathrm{~b}$.

Guo, J., Su, T., Li, Z., Miao, Y., Li, J., Liu, H., Xu, H., Cribb, M., and Zhai, P.: Declining frequency of summertime local-scale precipitation over eastern China from 1970 to 2010 and its potential link to aerosols, Geophys. Res. Lett., 44, 5700-5708, 2017.

Guo, J., Su, T., Chen, D., Wang, J., Li, Z., Lv, Y., Guo, X., Liu, H., Cribb, M., and Zhai, P.: Declining summertime local-scale precipitation frequency over China and the United States, 19812012: The disparate roles of aerosols, Geophys. Res. Lett., 46, 13281-13289, 2019a.

Guo, J., Li, Y., Cohen, J., Li, J., Chen, D., Xu, H., Liu, L., Yin, J., $\mathrm{Hu}, \mathrm{K}$., and Zhai, P.: Shift in the temporal trend of boundary layer height trend in China using long-term (1979-2016) radiosonde data, Geophys. Res. Lett., 46, 6080-6089, 2019b.

Haywood, J. and Boucher, O.: Estimates of the direct and indirect radiative forcing due to tropospheric aerosols: A review, Rev. Geophys., 38, 513-543, 2000.
He, Q. S., Li, C. C., Mao, J. T., Lau, A. K. H., and Li, P. R.: A study on the aerosol extinction-to-backscatter ratio with combination of micro-pulse LIDAR and MODIS over Hong Kong, Atmos. Chem. Phys., 6, 3243-3256, https://doi.org/10.5194/acp-6-32432006, 2006.

Holben, B. N., Eck, T. F., Slutsker, I., Tanre, D., Buis, J. P., Setzer, A., Vermote, E., Reagan, J. A., Kaufman, Y. J., Nakajima, T., and Lavenu, F.: AERONET - A federated instrument network and data archive for aerosol characterization, Remote Sens. Environ., 66, 1-16, 1998.

Hooper, W. P. and Eloranta, E. W.: Lidar measurements of wind in the planetary boundary layer - the method, accuracy and results from joint measurements with radiosonde and kytoon, Bound.Lay. Meteorol., 25, 990-1001, 1986.

Huang, J., Guo, J., Wang, F., Liu, Z., Jeong, M.-J., Yu, H., and Zhang, Z.: CALIPSO inferred most probable heights of global dust and smoke layers, J. Geophys. Res.-Atmos., 120, 50855100, 2015.

Huang, Q., Cai, X., Wang, J., Song, Y., and Zhu, T.: Climatological study of the Boundary-layer air Stagnation Index for China and its relationship with air pollution, Atmos. Chem. Phys., 18, 7573-7593, https://doi.org/10.5194/acp-18-7573-2018, 2018.

Huang, X., Wang, Z., and Ding, A.: Impact of Aerosol-PBL Interaction on Haze Pollution: Multiyear Observational Evidences in North China, Geophys. Res. Lett., 45, 8596-8603, 2018.

Jacobson, M. Z.: Strong radiative heating due to the mixing state of black carbon in atmospheric aerosols, Nature, 409, p. 695, 2001.

Kendall, M. G.: Rank Correlation Methods, Griffin, London, 1-202, 1975.

Klett, J. D.: Lidar inversion with variable backscatter/extinction ratios, Appl. Optics, 24, 1638-1643, 1985.

Kuang, Y., Zhao, C. S., Tao, J. C., Bian, Y. X., and Ma, N.: Impact of aerosol hygroscopic growth on the direct aerosol radiative effect in summer on North China Plain, Atmos. Environ., 147, 224 233, 2016.

Li, J., Li, C., Zhao, C., and Su, T.: Changes in surface aerosol extinction trends over China during 1980-2013 inferred from qualitycontrolled visibility data, Geophys. Res. Lett., 43, 8713-8719, 2016.

Li, Z., Niu, F., Fan, J., Liu, Y., Rosenfeld, D., and Ding, Y.: Longterm impacts of aerosols on the vertical development of clouds and precipitation. Nat. Geosci., 4, p. 888, 2011.

Li, Z., Lau, W. K. M., Ramanathan, V., Wu, G., Ding, Y., Manoj, M. G., Liu, J., Qian, Y., Li, J., Zhou, T., Fan, J., Rosenfeld, D., Ming, Y., Wang, Y., Huang, J., Wang, B., Xu, X., Lee, S. S., Cribb, M., Zhang, F., Yang, X., Zhao, C., Takemura, T., Wang, K., Xia, X., Yin, Y., Zhang, H., Guo, J., Zhai, P. M., Sugimoto, N., Babu, S. S., and Brasseur, G. P.: Aerosol and monsoon climate interactions over Asia, Rev. Geophys., 54, 866-929, https://doi.org/10.1002/2015RG000500, 2016.

Li, Z., Rosenfeld, D., and Fan, J.: Aerosols and their Impact on Radiation, Clouds, Precipitation and Severe Weather Events, Oxford Encyclopedia in Environmental Sciences, https://doi.org/10.1093/acrefore/9780199389414.013.126, 2017a.

Li, Z., Guo, J., Ding, A., Liao, H., Liu, J., Sun, Y., Wang, T., Xue, H., Zhang, H., and Zhu, B.: Aerosol and boundary-layer interactions and impact on air quality, Natl. Sci. Rev., 4, 810-833, https://doi.org/10.1093/nsr/nwx117, 2017b. 
Liu, J., Zheng, Y., Li, Z., Flynn, C., and Cribb, M.: Seasonal variations of aerosol optical properties, vertical distribution and associated radiative effects in the Yangtze Delta region of China, J. Geophys. Res.-Atmos., 117, D00K38, https://doi.org/doi.org/10.1029/2011JD016490, 2012.

Liu, S. and Liang, X.-Z.: Observed diurnal cycle climatology of planetary boundary layer height, J. Climate, 22, 5790-5809, https://doi.org/10.1175/2010JCLI3552.1, 2010.

Lou, M., Guo, J., Wang, L., Xu, H., Chen, D., Miao, Y., Lv, Y., Li, Y., Guo, X., Ma, S., and Li, J.: On the relationship between aerosol and boundary layer height in summer in China under different thermodynamic conditions, Earth Space Sci., 6, 887-901, 2019.

Mann, H. B.: Nonparametric tests against trend, Econometrica, 13, 245-259, 1945.

Melfi, S. H., Spinhirne, J. D., Chou, S. H., and Palm, S. P.: Lidar observations of vertically organized convection in the planetary boundary layer over the ocean, J. Clim. Appl. Meteorol., 24, 806-821, 1985

Menon, S., Hansen, J., Nazarenko, L., and Luo, Y.: Climate effects of black carbon aerosols in China and India. Science, 297, 22502253, 2002.

Miao, Y., Guo, J., Liu, S., Wei, W., Zhang, G., Lin, Y., and Zhai, P.: The climatology of low-level jet in Beijing and Guangzhou, China, J. Geophys. Res.-Atmos., 123, 2816-2830, 2018.

Ministry of Ecology and Environment of China: National air quality release platform: hourly $\mathrm{PM}_{2.5}$, publicly release available at: http://106.37.208.233:20035/, last access: January 2020.

NASA: MERRA-2 reanalysis data, available at: https://disc. gsfc.nasa.gov/datasets?keywords=MERRA2\&page $=1$, last access: April 2019a.

NASA: AERONET Aerosol Inversions, available at: https://aeronet. gsfc.nasa.gov, last access: April 2019b.

Petäjä, T., Järvi, L., Kerminen, V. M., Ding, A. J., Sun, J. N., Nie, W., Kujansuu, J., Virkkula, A., Yang, X., Fu, C. B., Zilitinkevich, S., and Kulmala, M.: Enhanced air pollution via aerosol-boundary layer feedback in China, Sci. Rep., 6, 18998, https://doi.org/10.1038/srep18998, 2016.

Quan, J., Gao, Y., Zhang, Q., Tie, X., Cao, J., Han, S., Meng, J., Chen, P., and Zhao, D.: Evolution of planetary boundary layer under different weather conditions, and its impact on aerosol concentrations, Particuology, 11, 34-40, 2013.

Ramanathan, V. C. P. J., Crutzen, P. J., Kiehl, J. T., and Rosenfeld, D.: Aerosols, climate, and the hydrological cycle, Science, 294, 2119-2124, 2001.

Rienecker, M. M., Suarez, M. J., Gelaro, R., Todling, R., Bacmeister, J., Liu, E., Bosilovich, M. G., Schubert, S. D., Takacs, L., Kim, G. K., and Bloom, S.: MERRA: NASA's modern-era retrospective analysis for research and applications, J. Climate, 24, 3624-3648, 2011.

Ricchiazzi, P., Yang, S., Gautier, C., and Sowle, D.: SBDART: A research and teaching software tool for planeparallel radiative transfer in the Earth's atmosphere, B. Am. Meteorol. Soc., 79, 2101-2114, https://doi.org/10.1175/15200477(1998)079<2101:SARATS>2.0.CO;2, 1998.

Sawyer, V. and Li, Z.: Detection, variations and intercomparison of the planetary boundary layer depth from radiosonde, lidar, and infrared spectrometer, Atmos. Environ., 79, 518-528, 2013.
Smirnov, A., Holben, B. N., Eck, T. F., Dubovik, O., and Slutsker, I.: Cloud-screening and quality control algorithms for the AERONET database, Remote Sens. Environ., 73, 337-349, 2000.

Stull, R. B.: An Introduction to Boundary Layer Meteorology, Kluwer, 670-680, 1988.

Su, T., Li, J., Li, C., Xiang, P., Lau, A. K. H., Guo, J., Yang, D., and Miao, Y.: An intercomparison of long-term planetary boundary layer heights retrieved from CALIPSO, ground-based lidar, and radiosonde measurements over Hong Kong. J. Geophys. Res.Atmos., 122, 3929-3943, 2017a.

Su, T., Li, J., Li, C., Lau, A. K. H., Yang, D., and Shen, C.: An intercomparison of AOD-converted $\mathrm{PM}_{2.5}$ concentrations using different approaches for estimating aerosol vertical distribution, Atmos. Environ., 166, 531-542, $2017 \mathrm{~b}$.

Su, T., Li, Z., and Kahn, R.: Relationships between the planetary boundary layer height and surface pollutants derived from lidar observations over China: regional pattern and influencing factors, Atmos. Chem. Phys., 18, 15921-15935, https://doi.org/10.5194/acp-18-15921-2018, 2018.

Su, T., Li, Z., and Kahn, R.: A new method to retrieve the diurnal variability of planetary boundary layer height from lidar under different thermodynamic stability conditions, Remote Sens. Environ., 237, 111519, https://doi.org/10.1016/j.rse.2019.111519, 2020.

Tang, G., Zhang, J., Zhu, X., Song, T., Münkel, C., Hu, B., Schäfer, K., Liu, Z., Zhang, J., Wang, L., Xin, J., Suppan, P., and Wang, Y.: Mixing layer height and its implications for air pollution over Beijing, China, Atmos. Chem. Phys., 16, 2459-2475, https://doi.org/10.5194/acp-16-2459-2016, 2016.

Wallace, J. M. and Hobbs, P. V.: Atmospheric science: an introductory survey, Vol. 92, Elsevier, 2006.

Wang, H., Shi, G. Y., Zhang, X. Y., Gong, S. L., Tan, S. C., Chen, B., Che, H. Z., and Li, T.: Mesoscale modelling study of the interactions between aerosols and PBL meteorology during a haze episode in China Jing-Jin-Ji and its near surrounding region - Part 2: Aerosols' radiative feedback effects, Atmos. Chem. Phys., 15, 3277-3287, https://doi.org/10.5194/acp15-3277-2015, 2015.

Wang, H., Li, Z., Lv, Y., Xu, H., Li, K., Li, D., Hou, W., Zheng, F., Wei, Y., and Ge, B.: Observational study of aerosol-induced impact on planetary boundary layer based on lidar and sunphotometer in Beijing, Environ. Pollut., 252, 897-906, 2019.

Wang, J., Wang, S., Jiang, J., Ding, A., Zheng, M., Zhao, B., Wong, D. C., Zhou, W., Zheng, G., Wang, L., and Pleim, J. E.: Impact of aerosol-meteorology interactions on fine particle pollution during China's severe haze episode in January 2013, Environ. Res. Lett., 9, 094002, https://doi.org/10.1088/17489326/9/9/094, 2014.

Wang, Y., Khalizov, A., Levy, M., and Zhang, R.: New directions: Light absorbing aerosols and their atmospheric impacts, Atmos. Environ., 81, 713-715, 2013.

Wang, Y., Li, Z., Zhang, Y., Du, W., Zhang, F., Tan, H., Xu, H., Fan, T., Jin, X., Fan, X., Dong, Z., Wang, Q., and Sun, Y.: Characterization of aerosol hygroscopicity, mixing state, and $\mathrm{CCN}$ activity at a suburban site in the central North China Plain, Atmos. Chem. Phys., 18, 11739-11752, https://doi.org/10.5194/acp-18-117392018, 2018. 
Wang, Z., Huang, X., and Ding, A.: Dome effect of black carbon and its key influencing factors: a one-dimensional modelling study, Atmos. Chem. Phys., 18, 2821-2834, https://doi.org/10.5194/acp-18-2821-2018, 2018.

Wei, J., Huang, W., Li, Z., Xue, W., Peng, Y., Sun, L., and Cribb.: M. Estimating 1-km-resolution $\mathrm{PM}_{2.5}$ concentrations across China using the space-time random forest approach, Remote Sens. Environ., 231, 111221, https://doi.org/10.1016/j.rse.2019.111221, 2019a.

Wei, J., Li, Z., Guo, J., Sun, L., Huang, W., Xue, W., Fan, T., and Cribb, M.: Satellite-derived $1 \mathrm{~km}$-resolution $\mathrm{PM}_{1}$ concentrations from 2014 to 2018 across China, Environ. Sci. Technol., 53, 13265-13274, https://doi.org/10.1021/acs.est.9b03258, 2019b.

Yang, D., Li, C., Lau, A. K. H., and Li, Y.: Long-term measurement of daytime atmospheric mixing layer height over Hong Kong, J. Geophys. Res.-Atmos., 118, 2422-2433, 2013.

Zhang, W., Guo, J., Miao, Y., Liu, H., Song, Y., Fang, Z., He, J., Lou, M., Yan, Y., Li, Y., and Zhai, P.: On the summertime planetary boundary layer with different thermodynamic stability in China: A radiosonde perspective, J. Climate, 31, 1451-1465, 2018.
Zhang, Y., Li, Z., Zhang, Y., Li, D., Qie, L., Che, H., and Xu, H.: Estimation of aerosol complex refractive indices for both fine and coarse modes simultaneously based on AERONET remote sensing products, Atmos. Meas. Tech., 10, 3203-3213, https://doi.org/10.5194/amt-10-3203-2017, 2017.

Zhang, Y., Li, Y., Guo, J., Wang, Y., Chen, D., and Chen, H.: The climatology and trend of black carbon in China from 12-year ground observations, Clim. Dynam., 53, 5881-5892, https://doi.org/10.1007/s00382-019-04903-0, 2019.

Zhou, M., Zhang, L., Chen, D., Gu, Y., Fu, T. M., Gao, M., Zhao, Y., Lu, X., and Zhao, B.: The impact of aerosol-radiation interactions on the effectiveness of emission control measures, Environ. Res. Lett., 14, 024002, https://doi.org/10.1088/17489326/aaf27d, 2018.

Zou, J., Sun, J., Ding, A., Wang, M., Guo, W., and Fu, C.: Observation-based estimation of aerosol-induced reduction of planetary boundary layer height, Adv. Atmos. Sci., 34, 10571068, 2017. 